\title{
Methylene-bis-Norflavaspidic Acid, a Four-Ring Phloroglucinol Derivative from Dryopteris austriaca
}

\author{
ANERI PENTTILÄ and JACOBUS SUNDMAN
}

The Research Laboratories, Medica Ltd., Helsinki, Finland

\begin{abstract}
Phloroglucinol derivatives consisting of two rings linked by a methylene bridge constitute the general type of the compounds isolated from Dryopteris ferns. The compounds known hitherto, which consist of three rings likewise linked by methylene bridges, are the homologous mixture of filixic acids and trisaspidin, trisdesaspidin and trisflavaspidic acid. In this paper is presented the first four-ring phloroglucinol derivative isolated from Dryopteris. The new compound, called methylene-bis-norflavaspidic acid (I), is symmetrically composed of the following successive rings: butyrylfilicinic acid, two buty rylphloroglucinols and butyrylfilicinic acid with a methylene bridge between each ring. Independently of the number of rings in the naturally occurring phloroglucinol derivatives in Dryopteris, all compounds so far known show structural uniformity as to their inability to undergo further condensation.
\end{abstract}

By condensing butyrylfilicinic acid and butyrylphloroglucinol with formaldeBhyde the two-ring compound called norflavaspidic acid (II) is obtained. 1 As such, this compound has never been found in Dryopteris species, ${ }^{2}$ but it

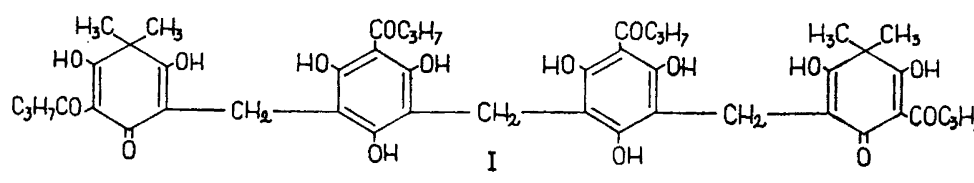<smiles></smiles>

constitutes a part of the molecules of several naturally occurring phloroglucinol derivatives composed of three rings, e.g. trisaspidin (III), trisdesaspidin (IV), trisflavaspidic acid $(\mathrm{V})$ and filixic acid $\mathrm{BBB}(\mathrm{VI}) .{ }^{1}$ In all these cases a methylene 


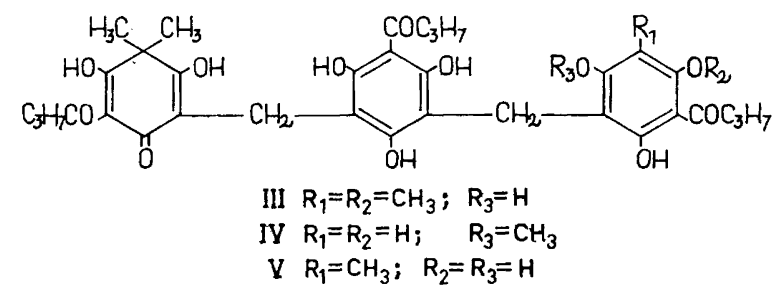

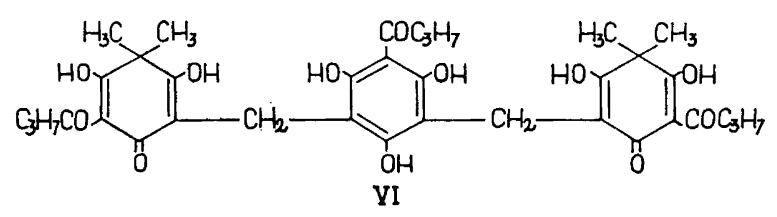

bridge links norflavaspidic acid with a monomer which is not capable of condensing further. Generally this is due to the fact that the monomer possesses only one free $\mathrm{CH}$-group available for condensation reactions. This is true of $\psi$-aspidinol, butyryl-3-methylphloroglucinol and butyrylfilicinic acid, which, condensed with norflavaspidic acid, yield the three-ring compounds trisaspidin, trisflavaspidic acid or filixic acid $\mathrm{BBB}$, respectively, none of them possessing any free $\mathrm{CH}$-groups and all therefore incapable of further condensation. Trisdesaspidin, composed of norflavaspidic acid and desaspidinol, seemingly forms an exception, because it still has a spare $\mathrm{CH}$-group available after condensation. However, if desaspidinol constitutes a part of a larger molecule of this type, its free CH-group exhibits a poor affinity for further condensation reactions. This is clearly denoted by the variety of compounds having desaspidinol as one moiety, e.g. desaspidin (VII), ${ }^{3}, 4$ phloraspin (VIII), ${ }^{5}$ phloraspyron (IX) ${ }^{6}$<smiles>[R]c1c([R20])c(CC2=C(O)C(C)(C)C(O)=C(C(O)[Al])C2=O)c(O)c(C(=O)OC)c1O</smiles><smiles>CCOc1c(O)c(C)c(O)c(Cc2c(O)cc(O)c(C(=O)O)c2O)c1O</smiles><smiles>[R4]CC1OC(=O)C=C(O)C1Cc1c(O)cc(O)c(C(=O)O)c1O</smiles><smiles>[X]Cc1c(Cc2c(O)c(C)c(O)c([SeH])c2O)c(O)c(C)c(O)c1OC</smiles>

Acta Chem. Scand. 17 (1963) No. 9 
and phloraspidinol $(\mathrm{X})^{6}$, none of which can easily be made to condense with formaldehyde to form symmetrical four-ring molecules. Desaspidinol, therefore, is one of the typical end-compounds showing no tendency to undergo further condensation.

More generally, all naturally occurring phloroglucinol derivatives so far isolated from Dryopteris species fall structurally within the category of compounds not capable of further condensation. This limitation throws new light<smiles>COc1cc(O)c(C(=O)O)c(O)c1</smiles>

on the natural occurrence of aspidinol (XI) in Dryopteris. Owing to its free $\mathrm{CH}$-group aspidinol can be condensed to form two-ring compounds, e.g. paraaspidin (XII), ${ }^{7}$ phloraspidinol ${ }^{6}$ and methylene-bis-aspidinol. ${ }^{8}$ Since aspidinol is capable of condensation reactions, it ought not to be included among the naturally occurring phloroglucinol derivatives. Our investigations concerning Finnish Dryopteris species have verified this result the details of which will be published later. 9

The non-occurrence of norflavaspidic acid in Dryopteris must be considered to follow from its ability to condense further, owing to the presence of the free $\mathrm{CH}$-group of the butyrylphloroglucinol nucleus. This theory is supported by the detection and isolation of the new phloroglucinol derivative presented in this paper, which has been shown to be composed of two norflavaspidic acids linked by a methylene bridge to form a symmetrical four-ring structure. The new compound, methylene-bis-norflavaspidic acid, has no free CH-groups and therefore fulfils the conditions required for its occurrence in Dryopteris rhizomes.

Methylene-bis-norflavaspidic acid appeared to be very sparingly soluble in methanol and could therefore be precipitated by addition of methanol to its solutions prepared in various solvents such as acetone, chloroform and isopropanol. The residue after the technical isolation of desaspidin from Dryopteris extract was used as source material for isolation of methylene-bis-norflavaspidic acid. The dried residue was dissolved in isopropanol and methanol was added. The precipitate gradually formed contained methylene-bis-norflavaspidic acid together with filixic acid BBB, some unknown compounds and small amounts of albaspidin and trisaspidin. After repeated precipitations with methanol from the other solvents mentioned, column chromatography on silica gel was carried out. Effective purification was achieved with benzene as eluant, but nevertheless slight decomposition was observed during the chromatography. The best fractions were combined and recrystallized from acetone. Methylene-bis-norflavaspidic acid, although chemically pure, melted unsharply in the temperature range $158-165^{\circ}$, simultaneously undergoing slow decomposition.

Alkaline cleavage of methylene-bis-norflavaspidic acid yielded butyrylfilicinic acid, butyrylphloroglucinol and butyryl-3-methylphloroglucinol, all identified by paper chromatography. These decomposition products were the same 
as those obtained by the alkaline cleavage of filixic acid BBB ${ }^{10}$ and trisflavaspidic acid. ${ }^{1}$ However, on account of the molecular weight determination a larger molecule was ascribed to the new compound, the determination being in good agreement with the formula $\mathrm{C}_{47} \mathrm{H}_{56} \mathrm{O}_{16}$ and thereby indicating a fourring molecule. The structure $(\mathrm{I})$ of methylene-bis-norflavaspidic acid based on these results was further confirmed by synthesis.

The synthesis of norflavaspidic acid was performed as previously described. ${ }^{1}$ Highly purified crystalline norflavaspidic acid, melting at $119-121^{\circ}$, was used for the synthesis of methylene-bis-norflavaspidic acid, which was carried out by condensing norflavaspidic acid with formaldehyde in dilute alkaline solution. Besides methylene-bis-norflavaspidic acid, the synthetic mixture contained considerable amounts of filixic acid BBB and some unknown compounds apparently formed through decomposition. Purification was carried out in the same way as the purification of natural methylene-bis-norflavaspidic acid, including precipitations with methanol from various solvents and column chromatography on silica gel. The pure synthetic methylene-bis-norflavaspidic acid melted unsharply at $158-165^{\circ}$ with decomposition, and had the same decomposition range when mixed with natural methylene-bis-norflavaspidic acid.

On paper chromatography 11 on buffered and formamide-impregnated papers developed with cyclohexane-chloroform (1:1) methylene-bis-norflavaspidic acid has the $R_{F}$-values listed in Table 1 . With the aid of these values and the red colour produced with the tetrazotized di-o-anisidine reagent methylene-bis-norflavaspidic acid can well be distinguished from all other naturally occurring phloroglucinol derivatives.

\section{EXPERIMENTAL}

Isolation of methylene-bis-norflavaspidic acid. The residue obtained after the technical isolation of desaspidin from Dryopteris austriaca extract was dried and dissolved in isopropanol. Methanol was added until the clear solution had turned turbid and the mixture was kept in a refrigerator for some days. The fine sediment formed was filtered off and precipitation with methanol was repeated from acetone and chloroform solutions. The methylene-bis-norflavaspidic acid obtained contained various amounts of filixic acid BBB and some unidentified compounds and was purified by chromatography through a column filled with silica gel. With benzene as eluant, filixic acid BBB was obtained in the first fractions, followed by methylene-bis-norflavaspidic acid, which in the beginning was relatively pure but later on contained considerable amounts of unknown compounds, apparently owing to decomposition during the chromatography. The best fractions were combined and recrystallized from acetone, and in this way methylene-bis-norflavaspidic

Table 1. The $R_{F}$ values of methylene-bis-norflavaspidic acid on papers buffered to $\mathrm{pH} 8.8 \cdot 8.4$.

\begin{tabular}{|c|c|c|c|c|c|}
\hline $\mathrm{pH}$ & 8.8 & 8.7 & 8.6 & 8.5 & 8.4 \\
\hline$R_{F}$ & 0.10 & 0.18 & 0.53 & 0.74 & 0.80 \\
\hline
\end{tabular}

Acta Chem. Scand. 17 (1963) No. 9 
acid was obtained in a pure state, melting, and simultaneously undergoing decomposition, at $158-165^{\circ}$. (Found: $\mathrm{C} 64.40 ; \mathrm{H} \mathrm{6.39}$. Calc. for $\mathrm{C}_{47} \mathrm{H}_{56} \mathrm{O}_{18}$ : C 64.38; $\mathrm{H} 6.39$.)

Alkaline cleavage of methylene-bis-norflavaspidic acid. Methylene-bis-norflavaspidic acid $(50 \mathrm{mg})$ was dissolved in sodium hydroxide $(20 \mathrm{ml}, 5 \%)$; zine dust $(100 \mathrm{mg})$ was added and the mixture was heated on a steam bath for 5 min. The cooled solution was filtered and diluted with water, acidified with dilute sulphuric acid and extracted with ether. The ethereal solution was evaporated to dryness and the residue dissolved in acetone and chromatographed on papers buffered to $\mathrm{pH}$ 5.0. Treatment with tetrazotized di-o-anisidine reagent produced a carmine red spot with the $R_{F}$ value 0.35 , identical with the spot obtained by chromatography of an authentic specimen of butyrylfilicinic acid, m.p. $98^{\circ}$.

The same decomposition mixture was further chromatographed on unbuffered papers with tetraline-acetic acid-water (10:10:1) solution. Two blue spots identical with butyryl-

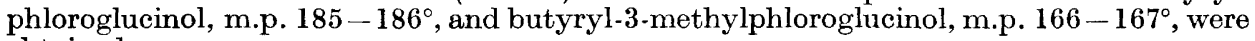
obtained.

Synthesis of methylene-bis-norflavaspidic acid. Norflavaspidic acid, m.p. 119-121 ${ }^{\circ}$, was synthesized as previously reported. It $(864 \mathrm{mg})$ was dissolved in potassium hydroxide $(30 \mathrm{ml}, 1 \%)$ and formaldehyde $(0.75 \mathrm{ml}, 4 \%)$ was added. The mixture was kept at room temperature for $1 \mathrm{~min}$ and acidified with dilute hydrochloric acid. The precipitate was filtered off and washed with water and methanol. The synthetic mixture was dissolved successively in acetone, chloroform and isopropanol and precipitated from each solution with methanol. The methylene-bis-norflavaspidic acid obtained contained minor amounts of filixic acid BBB and some unknown condensation and decomposition products from which it was freed by column chromatography on silica gel with benzene as eluant. Pure synthetic methylene-bis-norflavaspidic acid showed the melting range $158-165^{\circ}$ (decomp.). (Found: $\mathrm{C}$ 64.45; $\mathrm{H}$ 6.57. Calc. for $\mathrm{C}_{47} \mathrm{H}_{65} \mathrm{O}_{16}$ : $\mathrm{C}$ 64.38; $\mathrm{H}$ 6.39.)

\section{REFERENCES}

1. Penttilä, A. and Sundman, J. Acta Chem. Scand. 17 (1963). 2361.

2. Sundman, J. and Penttilä, A. To be published in Finska Kemistsamfundets Medd. 1964.

3. Aebi, A., Kapoor, A. L. and Büchi, J. Helv. Chim. Acta 40 (1957) 572.

4. Penttilä, A. and Sundman, J. Nord. Med. 67 (1962) 439.

5. Penttilä, A. and Sundman, J. Acta Chem. Scand. 15 (1961) 1777.

6. Penttilä, A. and Sundman, J. Acta Chem. Scand. 17 (1963) 1886.

7. Penttilä, A. and Sundman, J. Acta Chem. Scand. 16 (1962) 1251.

8. Boehm, R. Ann. 329 (1903) 269.

9. Penttilä, A. and Sundman, J. Unpublished results.

10. Penttilä, A. and Sundman, J. Acta Chem. Scand. 17 (1963) 191.

11. Penttilä, A. and Sundman, J. J. Pharm. Pharmacol. 13 (1961) 531.

Received June 19, 1963. 